\title{
Teaching and Research in Computer Science Experimental Course Based on PBL
}

\author{
Jun Rao \\ Tianjin University of Finance and Economics, China \\ rjnew@sina.com
}

Keywords: PBL; learning autonomy; flipped classroom

\begin{abstract}
This paper introduces the current situation of the research on the flipped classroom and learning autonomy at home and abroad, and analyzes the shortcomings of the current classroom teaching of computer science, which shows that it is a useful exploration to introduce PBL advanced teaching method into computer practice teaching. As an teaching example based on the concept of PBL, this paper elaborates the design and implementation of the teaching process in the database application practice course,.
\end{abstract}

\section{Introduction}

PBL is the abbreviation of Problem Based Learning, which is also called problem-driven teaching method. The teaching method of PBL method starts from the problems or tasks, provides students with knowledge and inspiration, inspire students to explore and solve problems, thereby promote the transformation of student learning methods, and develop students' learning autonomy.

In recent years, the concept of Flipped Classroom is popular in the global education sector, PBL method is one of the forms of the idea. With the rapid development of the classroom, many methods of new teaching reform are emerging, and the new trend of teaching reform is being presented. Therefore, improving the teaching method in "database application practice" course under the flip concept and PBL method, is a very meaningful educational exploration.

\section{Literature Review}

In 1980, Barrows \& Tamblyn of the United States published "Problem-based learning: An approach to medical education", which is the first systematic structure of the problem-based learning model and its educational ideas are expounded. Afterwards, more and more European and American universities have introduced the teaching model in their field of professional education.

In many educational institutions to adopt and promote at the same time, on the teaching model of the theory and mode of operation has also been constantly added, development and improvement. Yang [1], Victori [2], Wang [3], He [4] and Hua [5] have done a lot of research on how to promote students' autonomous learning and concluded that a good learning situation is to promote students to improve the ability of independent learning an important factor. Wang [6] proposed to improve the self-learning ability of students from the three aspects of teachers, students and teaching situations. $\mathrm{He}$ [7] put forward the situation teaching method, task-driven teaching method and heuristic teaching method under the support of information technology, which promotes effective communication between teachers and students, and actively carry out self-learning and collaborative learning.

At present, the problem-based learning model has been recognized by many international organizations and educational institutions, and has been widely used in a variety of teaching situations, up to the postgraduate level of teaching, down to primary and secondary schools and even kindergarten education; The teaching of a specific course unit can greatly expand the teaching of the entire degree course. 
However, in China, because the PBL method highlights the students in the classroom initiative, in the form of the traditional classroom is reversed, so its localization practice, not only need the necessary technical resources conditions, but also need to change the traditional, innovative courage.

\section{Current Difficulties}

This paper mainly studies how to apply the PBL method in the course of "database application practice", overcomes the shortcomings of the traditional teaching methods, and establishes a teaching mode suitable for the practice of the course, so that students become the main body of the classroom. At the same time to explore a reasonable set of performance evaluation methods, scientific evaluation of student learning effect.

The research goal is to strengthen the teaching interaction, improve the teaching effect, stimulate the students 'enthusiasm for learning and cultivate the students' ability of autonomous learning through the implementation of new teaching methods.

The traditional computer professional teaching mainly has the following four aspects:

(1) Emphasis on classroom teaching, experimental time is insufficient, leading to the theory and practice out of touch. Take the experimental course of the database course as an example, the experimental class is 32 hours. According to the requirements of the course, students in the experimental class to understand the basic management of the database, master a variety of data query, update the use of skills to complete the database system design and development. Experimental teachers usually have to demonstrate the steps of the operation, leaving the students to do their own hands-on experiment time is very tense.

(2) Simplification of teaching model, the lack of innovation. At present, limited to the traditional teaching evaluation mechanism, the teacher's classroom innovation is not enough, and more focused on the knowledge point of teaching. Immediately want to implement case teaching, due to time constraints, can only be given by the teacher demonstration steps, students in strict accordance with the steps to set the parameters, this step by step simple imitation, students can only passively accept knowledge, can not actively participate in teaching Activities, can not fully mobilize the initiative and creativity of students to learn.

(3) Lack of interaction on the machine, student differences difficult to balance. In the experimental class on the machine counseling, it is the mainly difficulty for a teacher to face 40 or more students. This type of counseling makes the workload of teachers increased, a limited time, a teacher can not organize a group of cooperative learning, discussion and other experimental activities, but also can not take into account all students, can not implement the difference of teaching, resulting in different levels of information technology Students have more complaints about this experimental course, mixed, reducing the positive initiative of students to learn.

(4) Teaching assessment methods single, one-sided. Student achievement should not only include works, but also depends on their learning process, to see the students learning attitude, ability to cooperate and examine the students' learning ability is really improved. However, due to the lack of necessary curriculum management system, students can not save the learning process, used to evaluate the effect of students learning only each experimental work, this evaluation is too single, can not really achieve the formation of evaluation.

Obviously, the traditional computer professional course teaching is in trouble, need to use the new teaching mode and way to reform the experimental teaching process and methods to solve the existing problems in experimental teaching.

\section{Implementation}

The PBL method is applied to the course of "database application practice" to develop practical problems in the form of "gradual iteration", and construct the teaching model based on PBL method. With the problem first, through the expansion of thought, theory, information integration, 
investigation and study, case analysis, this article discusses, this article practice and other aspects of progressive training, so that students have an open, diverse, interactive learning opportunities.

(1) students were freely combined into a team, which carries out teaching activities Research teaching should be a small class, the number of about 30 people, the students grouped, composed of team, all activities to "team" as a unit to strengthen the students The team consciousness, to cultivate their team spirit. Students in the classroom or laboratory, by the teacher organization, random questions, the students to the team, the students in the classroom, the teacher, the students, the students, the students, the students, the students, the students, the students, For the unit to explain, other team questioned; teacher comments, summary.

(2) To create problem situations, problem-oriented organization of teaching content created by the teacher to create problems, and then guide students in a certain teaching situation through the initiative to find and solve problems and access to knowledge and training capacity, while emphasizing the interaction between teachers and students Discussion. "Computer composition principle" course content, theoretical strong, traditional one-way teaching method is easy to make students feel boring, loss of learning initiative. Through the creation of problem situations, problem-oriented guide students to take the initiative to explore, to develop students learning ability and innovation ability.

(3) a variety of methods simultaneously, with interest to drive the organization of teaching methods in teaching methods, adhere to the heuristic, problem-driven teaching; teaching form on the teacher's teaching at the same time, supplemented by special discussion, student participation teaching, innovation Experiment and other forms, the traditional teacher-centered classroom teaching model into a student-centered teaching model.

(4) a wide range of assessment methods to focus on the implementation of the examination reform traditional assessment methods to the end of the end of the main test, resulting in a lot of students usually learning initiative is poor, pre-test temporary surprise, post-test knowledge quickly returned to the teacher, affecting the quality of personnel training The Research teaching, should establish a diversified assessment model. Assessment standards focus on four focus: focus on the process, pay attention to practice, focus on capacity and innovation.

The whole process of teaching has always been to achieve a "good" database system theme, learning in the user needs and limited development resources to achieve a balance between the group discussion, role play and other interactive ways to stimulate students' primary learning motivation. Through the creation of social scenarios, to solve the actual social problems, to stimulate students to design needs for the user's learning needs, to maximize participation in teaching activities, to create high quality and efficient flip classroom.

In the processing of teaching, we used these methods:

(1) Case-teaching method. According to the professional construction concept, combined with the characteristics of this course, in the teaching of the implementation of the "one case, through the" case teaching methods, the curriculum will be a complete integrity of the teaching performance management database development of this article with a class to show students, Their own tasks, to mobilize learning initiative. In the teaching organization to decompose the system into five relatively independent but mutual convergence of the module, according to the characteristics of students, from simple to complex, step by step to carry out teaching.

(2) Heuristic-teaching method. Teachers before teaching, carefully prepare lessons, carefully designed teaching content. In the course of lectures, give students the opportunity to ask questions, all students can solve the problem, encourage, inspire students to answer, develop students' awareness of participation. The use of heuristic teaching from shallow to deep, the use of life students exposed to the network to inspire students to think about the course to discuss and learn the unknown knowledge. The use of multimedia, electronic courseware and video and other auxiliary teaching methods, the abstract content of the visualization, specific.

(3) Discussion-in-teaching method. The students are divided into different learning groups, learning groups together to conduct a discussion, each student has put forward their own programs 
and recommendations, through collective discussion, and ultimately determine the better design. In the process of discussion to inspire each other to raise awareness, to promote students to actively think, to stimulate students to learn the enthusiasm to train students to study the spirit of the problem, training language skills and students' innovative thinking ability, training team awareness and spirit of collaboration.

\section{Summary}

This paper applys the problem-based learning method to the teaching process of "database application practice" course. Combining the teaching methods such as case teaching, heuristic teaching and discussion teaching, and constructs a more suitable teaching model for students major in computer science.The teaching model allows students to become the main body of teaching, teachers in the entire teaching activities into the teaching of the organizers and guides. This will not only stimulate students' enthusiasm for learning, but also the teacher from the monotony of repeated labor freed, give full play to both teachers and students both subjective initiative, improve teaching efficiency, improve teaching quality.

\section{Acknowledgement}

This paper was financially supported by the Teaching Reform Foundation of TUFE.

\section{References}

[1] Yang N D. Exploring a new role for teachers: Promoting learner autonomy[J]. System, 1998, 26(1): 127-135.

[2] Victori M, Lockhart W. Enhancing metacognition in self-directed language learning[J]. System, 1995, 23(2): 223-234.

[3] Wang Duqin. The Cultivation of College English Autonomous Learning Ability[J]. Foreign Language World, 2002 (5): 17-23.

[4] He Lianzhen.Self-learning and the Cultivation of Their Ability [J]. Foreign Language Teaching and Research, 2003, 35 (4): 287-289.

[5] Hua Weifen. Autonomous Learning Center - A New Language Learning Environment [J]. Foreign Language World,2001(5):41-45.

[6] Wang Jian,Guo Benyu. On the Cultivation of Students' Autonomous Learning Ability [J]. Education Exploration, 2009(3):12-13.

[7] He Jiling. The Reform of Teaching Methods of Teaching Chinese as a Foreign Language under the Support of Information Technology [J]. Science ,2008(6):126-130. 